\title{
An Evaluation Model for Deferred Project Development in Real Estate Investment
}

\author{
Ching-Hwang Wang, Meng-Tse Tsai*, Yu-Chun Huang and Hsu Tse-wei \\ Department of Construction Engineering, National Taiwan University of Science and Technology, Taipei, Taiwan
}

Received: 2 Feb. 2013, Revised: 3 Jun. 2013, Accepted: 4 Jun. 2013

Published online: 1 Sep. 2013

\begin{abstract}
In order to secure a higher return on investment, real estate developers often choose to adopt a deferred development strategy after acquiring land. However, this strategy involves a high degree of complexity and uncertainty. On this basis, this study develops a model to assess the value of deferred development projects. At any stage in the project, the model can inform a strategic choice to proceed with development, abandon the project, or defer development. At the same time, the model can be used to make a realistic assessment of the project value and the degree of risk involved. Based on the particular characteristics of deferred development in real estate investment projects, the model draws on theory on the waiting option and the abandonment option. Geometric Brownian Motion (GBM) is used to model the interdependent volatility in value associated with proceeding with development and abandoning the project, and Itō's lemma is applied to deduce stochastic volatility. The model can hence calculate the expected utility and rate of success of deferred development. Finally, case study analysis demonstrates that this model is an effective tool for evaluation of deferred development projects. It therefore provides a useful reference for real estate developers when making strategic decisions.
\end{abstract}

Keywords: real estate investment, real option, expanded net present value, deferred development

\section{Introduction}

Due to the high population density in Taiwan, the land of city tends to be very expensive. In practice, real estate developers adopt a deferred development strategy by waiting for the most opportune moment to develop the site after land purchase. As the decision-making process surrounding deferred development is complex, decision makers may choose at any time to either develop or resell the project site. But decision makers may also decide to defer the decision until a more opportune moment, giving themselves more time and information to anticipate changes in the market and creating the possibility of higher future returns on investment.

Traditionally, project evaluation for investment in the construction industry used net present value (NPV) to calculate project value. However, Trigeorgis and Manson ( 1987 ) [1] further argue the NPV method does not take into account future uncertainty, leading to discrepancies between anticipated results and what is actually produced. Trigeorgis and Manson suggest that the fair value of an investment project should be calculated by adding real option value to traditional NPV value to produce an expanded net present value (expanded NPV). This method effectively addresses the omission of the influence of uncertainty in traditional NPV methods, while at the same time taking into consideration the value of flexible management in decision making. On this basis, this study applies real option analysis to develop an evaluation model for project value in real estate investment. This evaluation model can provide a more realistic assessment of the real value of the project.

Titman (1985) [2] applies real option analysis to the study of real estate pricing and argues that uncertainty increases the value of undeveloped sites. Williams (1991) [3] calculates the most opportune time for site development and the most suitable development density. He points out that NPV flow may also be negative. Trigeorgis (1993) [4] proposes seven types of real option: waiting, abandonment, multi-stage, switch scale (expansion or contraction), switching, growth, and compound. Quigg (1993) [5] develops an option pricing model for undeveloped land based on future property prices and the costs of development. Grenadier (1996) [6] uses game theory to construct an equilibrium framework for strategic exercise of options. The evaluation model

\footnotetext{
*Corresponding author e-mail: olympiad99@gmail.com
} 
developed by Katia, Luciana, Francisco, Jose A and Jose $\mathrm{P}$ (2007) [7] is also able to account for the influence of the rate of sales on the success of the project. On this basis, they demonstrate the value of flexible management and using the most effective investment strategies at each stage. Farissi, Sahut and Bellalah (2008) [8] point out that information costs are necessary to cover the expenses necessary to be informed about an investment opportunity and guide decision making. Buttimer, Clark, and Ott (2008) [9] construct an options model for presales in real-estate development and shows that investors use presales as a way to manage risk. Ke, Diao, and Zhu (2011) [10] they construct a real option model suitable for real estate project investment decision making under high uncertainty in China.

\section{Basic concept of model development}

In the existing literature on real option theory, the waiting option and abandonment option are conceptually similar to the deferred development strategy. However, the assumptions behind these evaluation models do not reflect the particular characteristics of deferred development, as explained below:

The waiting option refers to a decision to defer a project until a suitable time to decide whether to proceed with development. The decision-making model can be expressed as follows: $E=\max \left(V_{T}-I_{T}, 0\right)$, where $E$ is the expected utility of the waiting option, $V_{T}$ is the value of the investment project at time $T$, and $I_{T}$ is input costs at time $T$.

The abandonment option refers to a decision to suspend or cancel an investment project in response to anticipated difficulties in the project. The decision making model can be expressed as follows: $E=\max \left(A-V_{T}, 0\right)$, where $E$ is the expected utility of the abandonment option, $V_{T}$ is the value of the investment project at time $T$, and $A$ is the value derived from abandoning the project.

However, the above real option models are not suitable for applying directly to deferred development strategies for real estate investment projects. This is because in the waiting option, if the choice is made not to proceed with development, the developer still has the land holding. However, the waiting option regards the utility derived from undeveloped land as zero, which is unrealistic since it ignores the benefits gained from holding the land. In addition, the abandonment option unrealistically regards the value derived from project abandonment as fixed, thereby failing to account for fluctuations over time in the value derived from project abandonment in deferred development projects.

Following the above discussion, this study develops a new evaluation model for deferred project development in real estate investment, shows in Figure 1. On the basis of the particular characteristics of deferred development in real estate, the model draws on theory on the "waiting option" and the "abandonment option. "GBM is used to model the interdependent volatility in value associated with proceeding with development and abandoning the project, and Itō's lemma is applied to deduce stochastic volatility. Decision makers will compare the utility derived from two investment choices and make the investment choice that delivers the greater benefits. Therefore, the deferred development strategy decision making model can be expressed as $\max \left(V_{T}-C_{V}, L_{T}-C_{L}\right)$. This study also uses MATLAB for coding to ensure that the model can be applied quickly and effectively.

\section{The Evaluation Model for Deferred Project Development}

\subsection{Calculating the Model Value Diffusion Process}

The value of proceeding with development $\left(V_{T}\right)$ and abandoning the project $\left(L_{T}\right)$ in the deferred development strategy displays uncertain volatility. In order to simulate this uncertain volatility, and based on the high degree of correlation between changes in the two investment choices, in this paper the value of proceeding with the development and abandoning the project follow dependent GBM, as shown in Equation (1) below.

$$
\begin{aligned}
d V & =\mu_{V} V_{0} d T+\sigma_{V} V_{0} d W_{1} \\
d L & =\mu_{L} L_{0} d T+\sigma_{L} L_{0} d W_{2}
\end{aligned}
$$

In the above formula, $V_{0}$ is the initial value of the development project, $L_{0}$ is the initial value of abandoning the project, $\mu_{V}$ is expected growth in the value of the development project, $\mu_{L}$ is expected growth in the value of abandoning the project, $\sigma_{V}$ is volatility in the value of the development project, $\sigma_{L}$ is volatility in the value of abandoning the project, and $d W_{1}$ and $d W_{2}$ are the correlation coefficient $\rho$ Wiener process.

Using dependent GMB, we can describe possible fluctuations in the path of both project values at future time $T$. However, in order to understand the distribution produced by this stochastic process at a given point in time $T$, we can regard the stochastic process described above as an Itō process. Using Itō's lemma, we can infer the distribution of the stochastic process at time $T$.

If $X=\ln v$ and $Y=\ln L$ are both Itō processes, their variation is measured as $d X(V, T)$ and $d X(L, T)$, as shown in Equation (2) below:

$$
\begin{aligned}
& d X(V, T) \\
& =\left[\mu_{V}(V, T) \frac{\partial X}{\partial V}+\frac{\partial X}{\partial t}+\frac{1}{2} \sigma_{V}^{2}(V, T) \frac{\partial^{2} X}{\partial V^{2}}\right] d T+\sigma(V, T) \frac{\partial X}{\partial V} d W_{1} \\
& d Y(L, T) \\
& =\left[\mu_{L}(L, T) \frac{\partial Y}{\partial L}+\frac{\partial Y}{\partial t}+\frac{1}{2} \sigma_{L}^{2}(L, T) \frac{\partial^{2} Y}{\partial L^{2}}\right] d T+\sigma(L, T) \frac{\partial Y}{\partial L} d W_{2}
\end{aligned}
$$


where $\frac{\partial X}{\partial V}=\frac{1}{V}, \frac{\partial^{2} X}{\partial V^{2}}=-\frac{1}{V^{2}}, \frac{\partial Y}{\partial L}=\frac{1}{L}, \frac{\partial^{2} Y}{\partial L^{2}}=-\frac{1}{L^{2}}, \frac{\partial Y}{\partial T}=0$.

After entering It $\bar{o}$ 's lemma, the equation is rearranged as shown in Equation (3) below:

$$
\begin{gathered}
d X(V, T)=\left(\mu_{V}-\frac{1}{2} \sigma_{V}^{2}\right) d T+\sigma_{V} d W_{1} \\
d Y(L, T)=\left(\mu_{L}-\frac{1}{2} \sigma_{L}^{2}\right) d T+\sigma_{L} d W_{2}
\end{gathered}
$$

Since $d X(V, T)=d \ln V$, then $d \ln V=\ln V_{T}-\ln V_{0}$, $d Y(L, T)=d \ln L$, and $d \ln L=\ln L_{T}-\ln L_{0}$, the equation is therefore rearranged as Equation (4) below.

$$
\begin{aligned}
& \ln V_{T}=\ln V_{0}+\left(\mu_{V}-\frac{1}{2} \sigma_{V}^{2}\right) d T+\sigma_{V} d W_{1} \\
& \ln L_{T}=\ln L_{0}+\left(\mu_{L}-\frac{1}{2} \sigma_{L}^{2}\right) d T+\sigma_{L} d W_{2}
\end{aligned}
$$

On the basis of the inferences drawn above, we show that when the values of project development and project abandonment both comply with dependent GMB, the value of future project development $V_{T}$ and project abandonment $L_{T}$ show lognormal distribution. The expected value of project development is $\ln V_{0}+\left(\mu_{V}-\frac{1}{2} \sigma_{V}^{2}\right)$, with variance $\sigma_{v}^{2} T$; the expected value of project abandonment is $\ln L_{0}+\left(\mu_{L}-\frac{1}{2} \sigma_{L}^{2}\right) T$, with variance $\sigma_{L}^{2} T$; the correlation coefficient is $\rho$. The future composition of the two values is expressed as shown in Equation (5) below:

$\left(\ln V_{T}, \ln L_{T}\right) \sim$

$N_{2}\left[\ln V_{0}+\left(\mu_{V}-\frac{1}{2} \sigma_{V}^{2}\right) T, \sigma_{v}^{2} T, \ln L_{0}+\left(\mu_{L}-\frac{1}{2} \sigma_{L}^{2}\right) T, \sigma_{L}^{2} T, \rho\right]$

From It $\bar{o}$ 's lemma, we find that the distribution of the values of project development and project abandonment at time $T$ is a lognormal distribution. Joining the two distributions together, we obtain a bivariate lognormal distribution. Therefore, for operational convenience, this study takes a logarithm for future project development and project abandonment, making $x=\ln V_{T}, y=\ln L_{T}$, then the value distribution probability function of project development and project abandonment at time $T$ is as shown in Equation (6) below:

$$
\begin{aligned}
F(p)= & \frac{1}{2 \pi b_{V} b_{L} \sqrt{1-\rho^{2}}} \exp \left\{-\frac{1}{2\left(1-\rho^{2}\right)}\left[\left(\frac{x-a_{V}}{b_{V}}\right)^{2}\right.\right. \\
& \left.\left.-2 \rho\left(\frac{x-a_{V}}{b_{V}}\right)\left(\frac{y-a_{L}}{b_{L}}\right)+\left(\frac{y-a_{L}}{b_{L}}\right)^{2}\right]\right\}
\end{aligned}
$$

where $a_{V}=\ln V_{0}+\left(\mu_{V}+\frac{1}{2} \sigma_{V}^{2}\right) T, b_{V}=\sigma_{v} \sqrt{T}, a_{L}=\ln L_{0}+$ $\left({ }_{L}+\frac{1}{2} \sigma_{L}^{2}\right) T, b_{L}=\sigma_{L} \sqrt{T}$.

\subsection{Calculating Utility in the Model}

Using dependent GBM to simulate the volatility of the two project options for period $T$, under logarithmic state the project values are combined into a bivariate lognormal distribution, shown in Figure 2. In the figure, the elliptical area represents the scope of project development and project abandonment outcomes, the $X$ axis represents the value of project development $\ln \left(V_{T}\right)$, the $Y$ the value of project abandonment $\ln \left(L_{T}\right)$, the vertical dashed line represents the cost of project development $\ln \left(C_{V}\right)$, the horizontal dashed represents the cost of project abandonment $\ln \left(C_{L}\right)$, while the curved line represents the points at which the utility of project development matched the utility of project abandonment $\left(V_{T}-C_{V}=L_{T}-C_{L}\right)$.

When the utility of future project development is greater than project abandonment (when $V_{T}-C_{V} \geq L_{t}-C_{L}$ ), we expect decision makers will choose the project development mode of investment. Therefore the expected utility of project development at future time $T$ is represented by each utility value on the vertical line $\left(V_{T}-C_{V}\right)$ and the combined probabilities of these points.From Figure 2 we can see that if we want to achieve an integral linearity of expected utility, when the value of project development $\ln \left(V_{T}\right)$ increases, the corresponding upper limit of project abandonment value will also change. $V_{T}-C_{V} \geq L_{t}-C_{L}$ can be rearranged as $L_{t} \leq V_{T}-C_{V}+C_{L}$. Subsequently, $\log$ transformation is applied to the value of project development and project abandonment $\left(x=\ln V_{T}, y=\ln L_{T}\right)$, so the upper limit of integration of variable $y$ can be expressed as $c \leq \ln \left(V_{T}-C_{V}+C_{L}\right)$, while the range of integration of variable $\mathrm{x}$ extends from negative infinity to positive infinity. Therefore, the expected utility of project development is expressed as Equation (7), below:

$$
\begin{aligned}
& \int_{-\infty}^{\infty} \int_{-\infty}^{c}\left(e^{x}-C_{V}\right) \frac{1}{2 \pi b_{V} b_{L} \sqrt{1-\rho^{2}}} \exp \left\{-\frac{1}{2\left(1-\rho^{2}\right)}\left[\left(\frac{x-a_{V}}{b_{V}}\right)^{2}\right.\right. \\
& \left.\left.-2 \rho\left(\frac{x-a_{V}}{b_{V}}\right)\left(\frac{y-a_{L}}{b_{L}}\right)+\left(\frac{y-a_{L}}{b_{L}}\right)^{2}\right]\right\} d y d x
\end{aligned}
$$

On the other hand, expected utility of project abandonment at future time $T$ is represented by each utility value on the horizontal line $\left(L_{T}-C_{L}\right)$ and the combined probabilities of these points.Therefore, the expected utility of project abandonment is expressed as Equation (8), below:

$$
\begin{aligned}
& \int_{-\infty}^{d} \int_{-\infty}^{\infty}\left(e^{y}-C_{L}\right) \frac{1}{2 \pi b_{V} b_{L} \sqrt{1-\rho^{2}}} \exp \left\{-\frac{1}{2\left(1-\rho^{2}\right)}\left[\left(\frac{x-a_{V}}{b_{V}}\right)^{2}\right.\right. \\
& \left.\left.-2 \rho\left(\frac{x-a_{V}}{b_{V}}\right)\left(\frac{y-a_{L}}{b_{L}}\right)+\left(\frac{y-a_{L}}{b_{L}}\right)^{2}\right]\right\} d y d x
\end{aligned}
$$

Finally, taking the sum of the expected values of project development and project abandonment utility and applying returned present value using expected discount rate, we can find the expanded NPV of project deferment to time $T$, as shown in Equation (9).

$$
\left[E\left(V_{T}-C_{V}\right)+E\left(L_{T}-C_{L}\right)\right] / e^{R T}
$$

\subsubsection{Calculating Success Rate in the Model}


In order to evaluate risk produced by the strategic decision to defer project development, this study uses the probability distribution implicit in dependent GBM to calculate the probability that the utility of the delayed development strategy is greater than zero. This is calculated as the combined probability of $V_{T}-C_{V} \geq 0$ and $L_{T}-C_{L} \geq 0$, and defines the probabilities calculated above as the success rate for deferred project development. As shown in Figure 2, the rate of project success is the combination of the first, second, and fourth probability quadrants. In order to integrate the probability areas where the value of project utility is greater than zero, after inequality $\log$ transformation and rearrangement of $V_{T}-C_{V} \geq 0$ and $L_{T}-C_{L} \geq 0$, the range of integration of variable $x$ ranges from $\ln \left(C_{v}\right)$ to positive infinity, the range of integration of variable $y$ ranges from $\ln \left(C_{L}\right)$ to positive infinity. The calculation of the success rate of deferred project development is shown in Equation (10) below:

$$
\begin{aligned}
& \int_{\ln \left(C_{V}\right)}^{\infty} \int_{\ln \left(C_{L}\right)}^{\infty} \frac{1}{2 \pi b_{V} b_{L} \sqrt{1-\rho^{2}}} \exp \left\{-\frac{1}{2\left(1-\rho^{2}\right)}\left[\left(\frac{x-a_{V}}{b_{V}}\right)^{2}-\right.\right. \\
& \left.\left.2 \rho\left(\frac{x-a_{V}}{b_{V}}\right)\left(\frac{y-a_{L}}{b_{L}}\right)+\left(\frac{y-a_{L}}{b_{L}}\right)^{2}\right]\right\} d y d x
\end{aligned}
$$

\subsubsection{Setting Model Parameters}

This study uses MATLAB software to produce a program to deferred development evaluation model outlined above. After entering the relevant parameters, it is possible to calculate the expected utility of deferred development and project success rate. Parameters that must be entered into the model include:

1. Period of Deferral (T)

Period of deferral refers to the length of time dependent GMB extends for and represents how long decision makers allow a project to be deferred.

2. Expected Discount Rate (R)

The expected discount rate for the project refers to a decision maker's appraisal of what constitutes a reasonable return on investment. Generally, this can be calculated from Weighted Average Cost of Capital (WACC), shown in Equation (11) below:

$$
W A C C=\sum_{i=1}^{N} C_{i} \times W_{i}
$$

\section{Initial Value of the Development $\operatorname{Project}\left(V_{0}\right)$}

This study defines the initial value of the development project as the total present value of the income earned if the development project is started immediately. The expected revenue cash flow schedule is established on the basis the existing project construction plan, financing plan, and marketing plan. Finally, total present value is calculated based on the expected discount rate.

4. Initial Value of Project Abandonment $\left(L_{0}\right)$
This study defines the initial value of project abandonment as the income earned from immediately selling the site land. The site value may be assessed by either a bank valuation officer to obtain a realistic assessment of the revenue from selling the land.

5. Cost of Carrying out the Development Project $\left(C_{V}\right)$, Cost of Abandoning the Construction Project $\left(C_{L}\right)$ and Information Costs $\left(C_{W}\right)$

This study defines information costs $\left(C_{W}\right)$ as the extra costs incurred in deferring the project for a particular period. Information costs are evaluated as shown in Equation (12), below:

$$
\frac{e^{R n}-1}{e^{R}-1} C_{W}
$$

$C_{W}$ are the information costs incurred in deferring the project for a particular period, $\mathrm{n}$ is the number of periods of deferral, and $\mathrm{R}$ is the discount rate expected by decision makers.

This study defines the cost of carrying out the development project $\left(C_{V}\right)$ as the total costs necessary for project implementation. By adding the costs of carrying out the development project to the information costs associated with deferred project, we can calculate the present cost value of carrying out the project. The calculation of the total costs of carrying out the project is shown in Equation (13), below:

$$
C_{V}=C_{0}+\frac{e^{R n}-1}{e^{R}-1} C_{W}
$$

$C_{V}$ is the total price of carrying out the project, $C_{0}$ is the present cost value of project development, $C_{W}$ are the information costs incurred in deferring the project for a particular period, $R$ is the project's expected discount rate, $n$ is the number of periods of deferral.

This study defines the cost of abandoning the development project $\left(C_{L}\right)$ as the total costs associated with the abandoned project, primarily the purchase of land for the project. The calculation of the total costs of abandon the project is shown in Equation (14), below:

$$
C_{L}=C_{1} \times e^{R T}+\frac{e^{R n}-1}{e^{R}-1} C_{W}
$$

$C_{L}$ is the price of abandoning the project, $C_{1}$ is the estimated cost of project abandonment, $C_{W}$ are the information costs incurred in deferring the project for a particular period, $R$ is the project's expected discount rate, $n$ is the number of periods of deferral.

6.Growth in the Value of the Development Project $\left(\mu_{V}\right)$ and Volatility in the Value of the Development Project $\left(\sigma_{V}\right)$

This study defines growth in the value of the development project $\left(\mu_{V}\right)$ as representing expected future growth trends in project value and volatility in the value of the development project $\left(\sigma_{V}\right)$ as representing the probability that the project value deviates from the expected value to assess the future scope of change in project value.However, estate projects are characterized by their uniqueness and complexity, meaning that past 
experiences and historical data cannot accurately predict future project volatility.

Based on the above discussion, this paper uses generalized auto regressive conditional heteroskedasticity (GARCH) to analyze the influence of the overall economy on volatility in house prices.This volatility is then entered into the real estate cash flow model and a Monte Carlo simulation is carried out to obtain the growth rate $\left(\mu_{V}\right)$ and volatility $\left(\sigma_{V}\right)$ in the value of the development project, as shown in Figure 3.Through the process of parameter calculation established in this study, a reasonable evaluation of the growth rate $\left(\mu_{V}\right)$ and volatility $\left(\sigma_{V}\right)$ in the value of the development project can be used as parameters in a subsequent evaluation model. The detailed calculation is shown in Appendix 1.

7. Growth in the Value of Project Abandonment $\left(\mu_{L}\right)$ and Volatility in the Value of the Project Abandonment $\left(\sigma_{L}\right)$

The growth in the value of project abandonment represents the expected growth trends in the value of the project site, while volatility in the value of the development abandonment represents the probability that the value of the project site deviates from the expected value. This study uses an index of historical land values in Taiwan produced by the Department of Land Administration and calculates $\left(\mu_{L}\right)$ and volatility $\left(\sigma_{L}\right)$ in the value of the project abandonment using a GARCH model as shown in Appendix 1.

8. Correlation Coefficient between the Value of Project Development and the Value of Project Abandonment $(\rho)$

The correlation coefficient represents the correlation between the direction in fluctuation of the value of project development and abandonment. This study uses historical house price indicators to deduce the value of project developments in each year. Subsequently, we use historical land value indicators and information on the value of development projects in each year. The calculation is shown in Equation (15), below:

$$
\rho=\frac{\sum_{i=1}^{n}\left(V_{i}-\bar{V}\right)\left(L_{i}-\bar{L}\right)}{\sqrt{\sum_{i=1}^{n}\left(V_{i}-\bar{V}\right)^{2} \times\left[\sum_{i=1}^{n}\left(L_{i}-\bar{L}\right)^{2}\right]}}
$$

\section{Case Study Analysis}

We test the evaluation model for deferred project development in real estate investment developed in this study with an actual case from Taipei City. At the same time, we demonstrate the utility of the model by comparing it with the traditional waiting option and NPV option

\subsection{Information on the Case Study}

We first test the evaluation model for deferred project development in real estate investment developed in the study with an actual case from Taipei City. Detailed information about the case can be found in Table 1 .

\subsection{Model Parameter Analysis}

1. Period of Deferral $(T)$ and Project Expected Discount Rate $(R)$

This study establishes a maximum period of deferral of ten years. The project expected discount rate $(R)$ is calculated according to Equation (11) as 13\%.

2. Initial Value of the Development Project $\left(V_{0}\right)$ and Initial Value of Project Abandonment $\left(L_{0}\right)$

Initial Value of the Development Project is calculated according to the revenue cash flow table and basis at the project discount rate of $13 \%$, producing a project revenue present value of NT\$227.52 million. On the other hand, this study defines the initial value of project abandonment as the income earned from immediately selling the site land. According to the bank assessment, the initial value of project abandonment is NT $\$ 98.28$ million.

3. Cost of Carrying out the Development Project $\left(C_{V}\right)$, Cost of Abandoning the Construction Project $\left(C_{L}\right)$ and Information Costs $\left(C_{W}\right)$

Information costs for every month the project is deferred total NT $\$ 140,000$ for loan interest on land purchase. The cost of carrying out the development project is calculated according to the cost cash flow table and basis at the project discount rate of $13 \%$, producing project present cost value of NT $\$ 210.08$ million. The cost of abandoning the development project $\left(C_{L}\right)$ are the total costs associated with the abandoned project, namely the purchase of land for the project. Therefore the cost of abandoning the project is $\$$ NT98.28 million.

4. Growth in the Value of Project Development and Project Abandonment $\left(\mu_{V} \mu_{L}\right)$ and Volatility in the Value of Project Development and Project Abandonment $\left(\sigma_{V} \sigma_{L}\right)$

We use an index of house prices in Taipei City as the basis for time series analysis on growth rate and volatility in project value. Using GARCH model for analysis, the time series for house prices in new development projects is ARMA(3,3)-GARCH(1,1). The model coefficients are shown in Table 2, below. Using this model, annual house price volatility is calculated as $15.98 \%$, while annual house price growth is calculated as $4.5 \%$. The results of the project revenue present value simulation are shown in Figure 4, then we calculate growth rate as $\left(\mu_{V}\right) 2.92 \%$ and volatility $\left(\sigma_{V}\right)$ as $21.88 \%$. Using the same method, we calculate growth rate in the value of project abandonment $\left(\mu_{L}\right)$ as $3.9 \%$ and volatility $\left(\sigma_{L}\right)$ as $22.39 \%$. The 
correlation coefficient $(\rho)$ between the value of project development and abandonment is 0.8765 .

\subsection{Application of the Model}

When the parameters discussed above are entered into the model, the MATLAB program developed in this study is used for parameter conversion and processing, shown in Table 3. Subsequently, parameters for project deferral to a given year ( $a_{V}, b_{V}, a_{L}$ and $b_{L}$ so on) are entered in to the probability model to establish a distribution probability function for each year. Integrals are then added for the area where project development or project abandonment takes place to produce a discount rate (as shown in Figures 5 and 6) and obtain the expected present value of project development and project abandonment. Combining these two values, we can obtain the models expected utility value. In addition, based on the distribution probability function for each year, the area in the model where the value of project development or project abandonment is greater than zero (as shown in Figure 7) show the rate of success, enabling calculation of the level of risk in deferred development projects.

Using the deferred development evaluation model produced in this study, we can obtain the expected utility and rate of success for a project deferred for between one and ten periods for our real estate development case. As Table 4 shows, in the project examined, analysis of deferred development using the model produces an initial rise but subsequent fall in expected utility value over time. However, the rate of success shows a constant decline from its initial value.

Our study shows that the fall in expected utility over time is the caused by the fact that anticipated growth in the value of project development and project abandonment is far lower that the discount rate demanded by decision makers. In addition, the continuous increase in information costs reduces total project utility. However, the analysis also shows that when the project is only deferred for a short time period, the project utility actually increases, demonstrating that the flexibility to defer the project in the short term can effectively deliver greater benefits for the real estate developer.

In addition, in order to verify the validity of this model, NPV and the waiting option are used to evaluate the utility of project deferment for ten years for the case examined in this study. The results of the NPV and waiting option evaluation are then compared with our evaluation model, as shown in Table 4. As the table shows, NPV evaluation produced broadly similar results to our model, but the NPV model evaluation results are slightly lower than the results from our model. This difference is because the NPV model assumes that project development will eventually proceed when calculating the expected utility of project deferral. The NPV fails to consider the value of project abandonment. Therefore, the difference in results between the NPV model and the model used in this study is the value produced by managerial flexibility. This comparison demonstrates the reasonableness of our model.

Next, in the waiting option model, project utility increases over time until it reaches the upper limit of the initial project value, as shown in Table 4. This is because the waiting option model only calculates expected utility when project utility is greater than zero and ignores both the utility of project abandonment and potential project losses. These assumptions are not realistic in the real world of real estate investment projects. As a result, the waiting option model seriously overestimates the utility of deferred project development. The above comparison of results from different evaluation models demonstrates that the model used more accurately reflects the actual operation of real estate investment projects. Furthermore, the model can be used to obtain the level of risk involved in deferred investment projects, providing important reference for investors.

This study also performs a sensitivity test on the deferred project development evaluation model to verify the stability of the model. First, sensitivity analysis $( \pm 20 \%)$ is carried out on growth rate in project development value and project abandonment value. As Figures 8 and 9 shows, higher growth rates in project development value and project abandonment value have a positive influence on utility value and rate of success. This result reflects the fact that decision makers tend to invest in areas where the project value growth rate is higher. Second, sensitivity analysis $( \pm 20 \%)$ is carried out on volatility in project development value and project abandonment value. As Figures 10 and 11 shows, higher volatility rates in project development value and project abandonment value have a positive effect on utility value of the project. However, at the same time, higher volatility rates also have a significant negative influence on the rate of success. This result reflects the fact that higher investment risk brings higher returns; investors are able to select an appropriate investment strategy based on their risk preferences. 


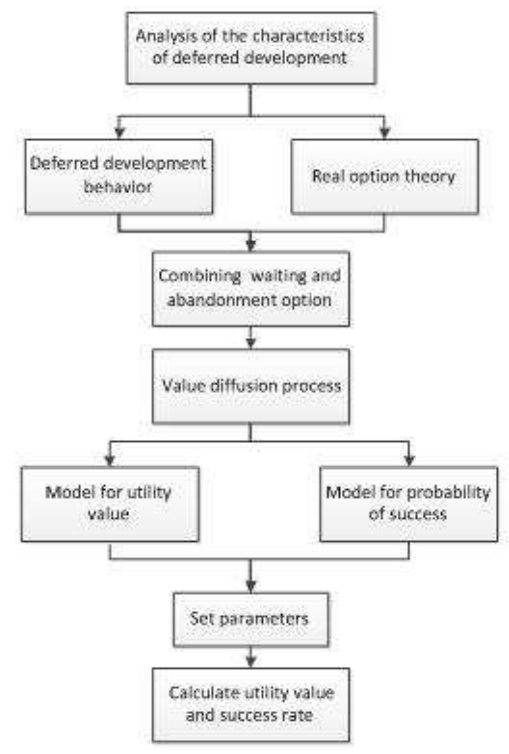

Fig. 1: Framework for Evaluation of Deferred Development

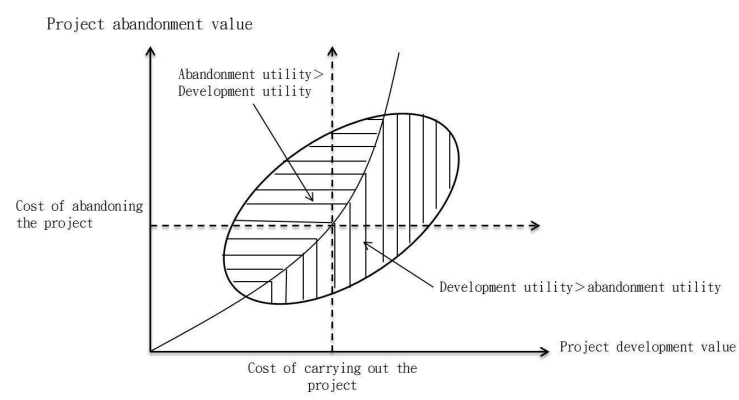

Fig. 2: Schematic Diagram of Decision Making in Deferred Development

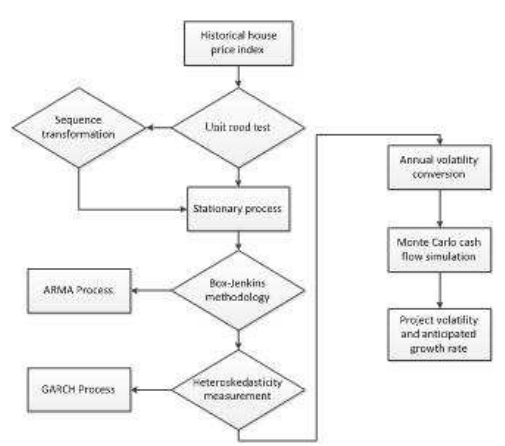

Fig. 3: Process Map for Calculating Project Volatility and Growth Rate

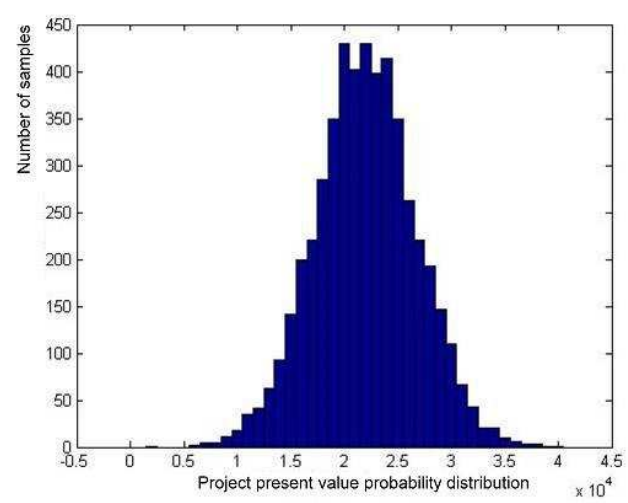

Fig. 4: Distribution Map for Project Revenue Present Value Simulation

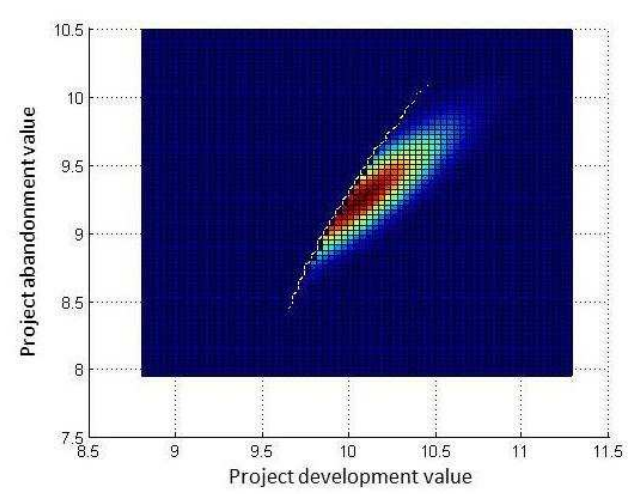

Fig. 5: Area Map for Project Implementation (project deferred two years

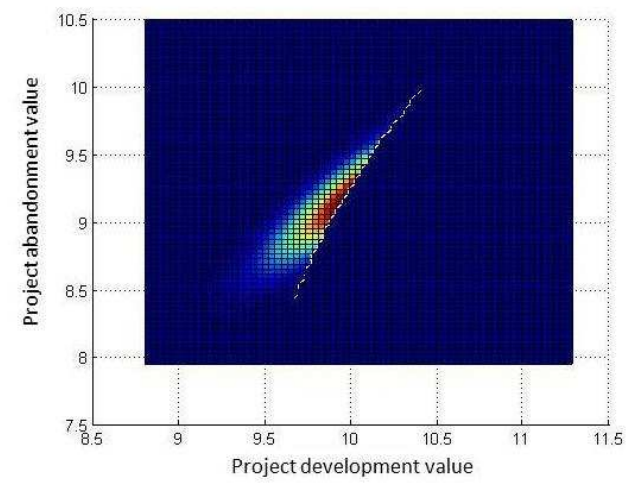

Fig. 6: Area Map for Project Abandonment (project deferred two years 


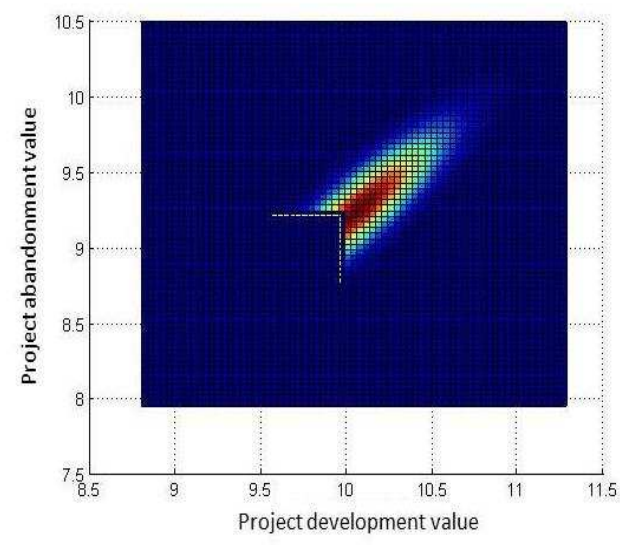

Fig. 7: Area Map Showing Project Development Utility Greater than Zero (project deferred two years

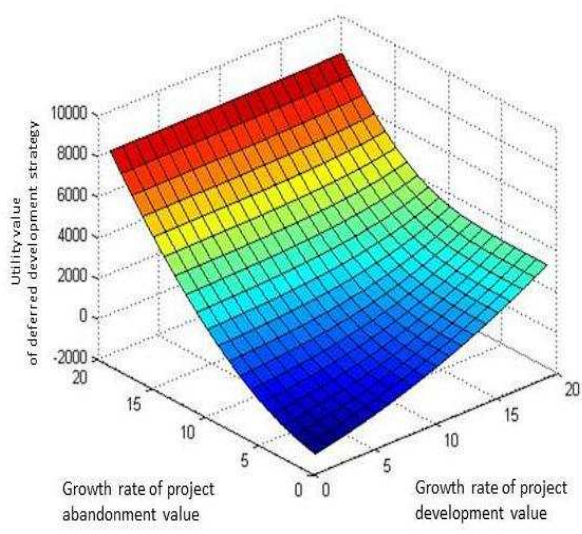

Fig. 8: The Influence of Growth Rate on Project Utility

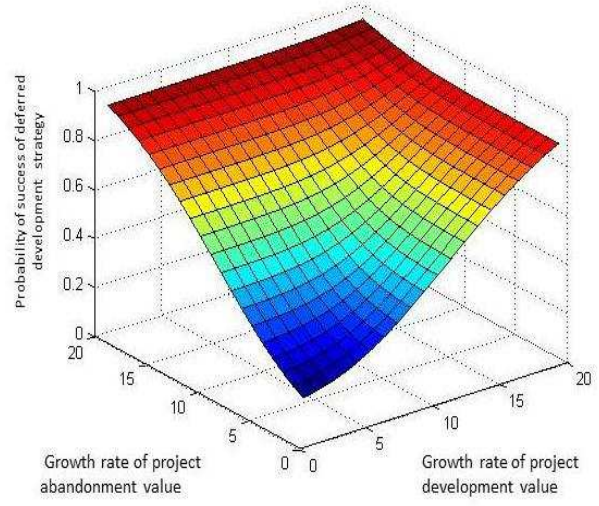

Fig. 9: The Influence of Growth Rate on Project Success Rate

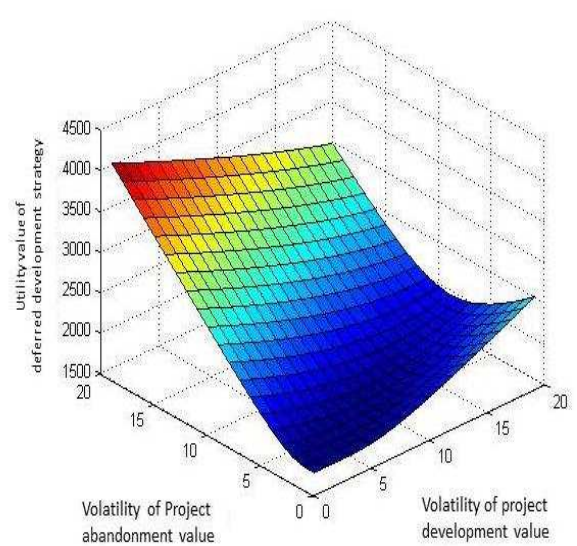

Fig. 10: The Influence of Volatility on Project Utility

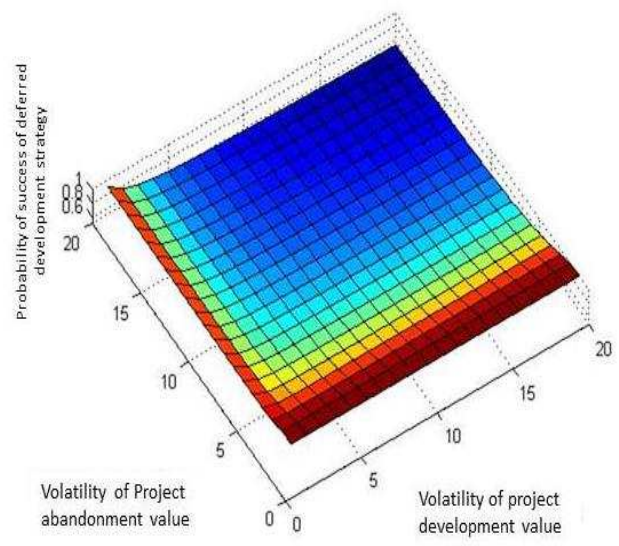

Fig. 11: The Influence of Volatility on Project Success Rate

Table 1: Project Details

\begin{tabular}{|c|c|c|c|c|c|c|c|}
\hline \multirow{4}{*}{ 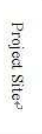 } & \multicolumn{2}{|c|}{ Site area } & \multicolumn{5}{|c|}{$277.7 \mathrm{M}^{2}$} \\
\hline & \multicolumn{2}{|c|}{ Current use, } & \multicolumn{5}{|c|}{ Parking Lote } \\
\hline & \multicolumn{2}{|c|}{ Land use zone } & \multicolumn{5}{|c|}{ Type 4 Residential Area } \\
\hline & \multicolumn{2}{|c|}{ Building Coverage Ratio } & \multicolumn{2}{|c|}{$50 \%$} & \multicolumn{3}{|c|}{ Plot ratio: $300 \%$} \\
\hline \multirow{10}{*}{ 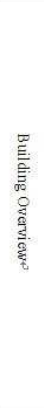 } & \multicolumn{2}{|c|}{ Building type } & \multicolumn{5}{|c|}{$\begin{array}{l}\text { Underground } 1 \text { floor, above ground } 7 \text { floors,roof protrusion } 3 \text { floors } \\
\text { residential building }\end{array}$} \\
\hline & \multicolumn{2}{|c|}{ Total Units } & \multicolumn{5}{|c|}{ Residential $=13$ units } \\
\hline & \multicolumn{2}{|c|}{ Total floor area } & \multicolumn{5}{|c|}{$138.85 \mathrm{~m} 2$} \\
\hline & \multicolumn{2}{|c|}{ Permitted floor area } & \multicolumn{5}{|c|}{$1,442 \mathrm{~m} 2$} \\
\hline & \multicolumn{2}{|c|}{ Public facilities ratio } & \multicolumn{5}{|c|}{$28.9 \%$} \\
\hline & \multicolumn{2}{|c|}{ Car parking spaces } & \multicolumn{5}{|c|}{$7(1$ regular and 6 mechanical $)$} \\
\hline & \multicolumn{2}{|c|}{ Excavation rate } & \multicolumn{5}{|c|}{$70 \%$} \\
\hline & \multicolumn{7}{|c|}{ Planned unit area } \\
\hline & th & $\begin{array}{c}\text { Ceiling height }- \text { - } \\
(M)\end{array}$ & $\begin{array}{c}\text { Indoor area } \\
\left(M^{2}\right)\end{array}$ & $\begin{array}{c}\text { Balcony } \\
\left(M^{2}\right)\end{array}$ & $\begin{array}{c}\text { Awning } \\
\left(M^{2}\right)\end{array}$ & $\begin{array}{c}\text { Public facilities } \\
\text { area }\left(M^{2}\right)\end{array}$ & Total \\
\hline & Total & 22.9 & 878.65 & 113.50 & $85.10 \mathrm{f}$ & 363.89 & 1441.14 \\
\hline
\end{tabular}


Table 2: ARMA(3,3)-GARCH(1,1) Model Coefficients

\begin{tabular}{ccc}
\hline mean equation & Coefficient estimates & z-Stastic \\
\hline$a_{0}$ & -0.057348 & -0.2104 \\
$a_{1}$ & 1.280251 & 1.0592 \\
$a_{2}$ & -0.648591 & -0.408 \\
$a_{3}$ & 0.073629 & 0.0983 \\
$b_{1}$ & -1.37882 & -1.1605 \\
$b_{2}$ & 0.804977 & 0.4536 \\
$b_{3}$ & 0.071648 & 0.063 \\
\hline variance equation & Coefficient estimates & z-Stastic \\
\hline$\alpha_{0}$ & 0.827019 & 2.0211 \\
$\alpha_{1}$ & 0.947382 & 2.2304 \\
$\beta_{1}$ & -0.026544 & -0.1586 \\
\hline
\end{tabular}

Table 3: Model Parameters for Deferment by Ten Years

\begin{tabular}{ccccccc}
\hline $\begin{array}{c}\text { Deferment } \\
\text { Period(T) }\end{array}$ & $a_{v}$ & $b_{v}$ & $a_{L}$ & $b_{V}$ & $c_{L}$ & $c_{V}$ \\
\hline 1 & 10.049 & $22.72 \%$ & 9.239 & $20.92 \%$ & 21179.0 & 11362.0 \\
2 & 10.055 & $32.13 \%$ & 9.285 & $29.59 \%$ & 21372.0 & 13109.0 \\
3 & 10.067 & $39.35 \%$ & 9.331 & $36.23 \%$ & 21592.0 & 15099.0 \\
4 & 10.078 & $45.44 \%$ & 9.378 & $41.84 \%$ & 21842.0 & 17364.0 \\
5 & 10.090 & $50.80 \%$ & 9.424 & $46.78 \%$ & 22128.0 & 19945.0 \\
6 & 10.101 & $55.65 \%$ & 9.470 & $51.24 \%$ & 22453.0 & 22883.0 \\
7 & 10.113 & $60.11 \%$ & 9.516 & $55.35 \%$ & 22823.0 & 26230.0 \\
8 & 10.124 & $64.26 \%$ & 9.562 & $59.17 \%$ & 23244.0 & 30041.0 \\
9 & 10.136 & $68.16 \%$ & 9.608 & $62.76 \%$ & 23724.0 & 34381.0 \\
10 & 10.147 & $71.85 \%$ & 9.654 & $66.15 \%$ & 24271.0 & 39324.0 \\
\hline
\end{tabular}

Table 4: Utility Value and Success Rate for Deferment by Ten Years According to Each Model

\begin{tabular}{ccccc}
\hline $\begin{array}{c}\text { Deferment } \\
\text { Period(T) }\end{array}$ & $\begin{array}{c}\text { Model } \\
\text { Expected } \\
\text { Value } \\
\text { (NT \$10,000) }\end{array}$ & $\begin{array}{c}\text { NPV } \\
\text { Deferred } \\
\text { Utility Value } \\
\text { (NT \$10,000) }\end{array}$ & $\begin{array}{c}\text { Waiting } \\
\text { Option Model } \\
\text { Utility } \\
\text { (NT \$10,000) }\end{array}$ & $\begin{array}{c}\text { Rate of } \\
\text { Success }\end{array}$ \\
\hline \hline 1 & 2124 & 1963 & 4432 & $63.97 \%$ \\
2 & 2240 & 2099 & 10094 & $59.46 \%$ \\
3 & 2254 & 2167 & 16229 & $57.19 \%$ \\
4 & 2233 & 2181 & 20631 & $55.65 \%$ \\
5 & 2194 & 2151 & 22445 & $54.42 \%$ \\
6 & 2132 & 2088 & 22742 & $53.34 \%$ \\
7 & 2046 & 1998 & 22752 & $52.33 \%$ \\
8 & 1939 & 1889 & 22752 & $51.34 \%$ \\
9 & 1817 & 1766 & 22752 & $50.34 \%$ \\
10 & 1685 & 1634 & 22752 & $49.30 \%$ \\
\hline
\end{tabular}

\section{Conclusion}

Based on the unique characteristics of deferred development in the industry, this study developed a comprehensive evaluation model for deferred development in real estate investment projects using real option theory. This model can both effectively assess the expected utility and rate of success for deferred development projects. The results of our analysis can form the basis for assessment of project value and level of risk by real estate developers.

As well as considering the value of project development in cases where a deferred development strategy has been adopted, our model also takes into account the influence of the value of project abandonment on deferred development strategies. At any point in time, decision makers may choose between proceeding with project development and abandoning the project based on which choice delivers the greater utility for the business. By taking into account changes in the value of project abandonment, our model improves on traditional evaluation models which produce misleading evaluation results because they either fail to account for the value of project abandonment or assume that the value of project abandonment is fixed. Our model can therefore objectively measure implied value and risk for real estate investment projects under conditions of future uncertainty.

The results of our study can effectively account for the decision-making behavior of real estate developers in cases of deferred project development and calculate expected utility value as well as degree of risk when such a strategy is adopted. The results therefore provide an important reference for project evaluation and choice of development strategy in the real estate industry.

\section{Acknowledgement}

The first author acknowledges the financial support by the FIRB project-RBID08PP3J-Metodi matematici e relativi strumenti per la modellizzazione e la simulazione della formazione di tumori, competizione con il sistema immunitario, e conseguenti suggerimenti terapeutici.

The authors are grateful to the anonymous referee for a careful checking of the details and for helpful comments that improved this paper.

\section{Appendix 1}

Calculation of Growth in the Value of the Development Project $\left(\mu_{V}\right)$ and Volatility in the Value of the Development Project $\left(\sigma_{V}\right)$

\section{STEP1: Unit Rood Test}

First, we perform a unit root test on the historical house price index to ensure a smooth data structure using the Augmented Dickey-Fuller suggested by Said and Dickey (1984) [11]. The calculation is shown in Equation (15), below:

$$
\Delta Y_{t}=\alpha_{0}+\alpha_{1} t+\alpha_{2} Y_{t-1}+\sum_{s=1}^{k} b_{s}(\Delta Y)_{t-s}+u_{t}
$$

Where, $\alpha_{0}$ is the drift term, $t$ is the deterministic trend term, and $u_{t}$ is the residual term. The test is used to verify the smoothness of the data.

STEP2: Autoregressive-Moving-Average Model (ARMA) Model

This study uses the Box and Jenkins[12] ARMA times series model. This method uses the price at time $p$ in the past and the residual term at time $q$ in the past to 
predict current price. Therefore, $\operatorname{ARMA}(p, q)$ is expressed as Equation (16), below:

$$
y_{t}=a_{0}+\sum_{i=1}^{p} a_{i} y_{t-i}+\varepsilon_{t}+\sum_{i=1}^{q} b_{i} \varepsilon_{t-i}
$$

Where, $\alpha_{0}$ is the drift term, $a_{i}$ and $b_{i}$ are regression coefficients, $y_{t}$ is the house price index at period $t$, and $\varepsilon_{t}$ is the residual term at period $t$.

In order to comply with the ARMA model requirements for residual terms, the study use Ljung-Box $\mathrm{Q}$ test and Jarque-Bera test to test whether or not the residual terms are white noise and the assumptions of normal distribution.

STEP3: Generalized Auto Regressive Conditional Heteroskedasticity (GARCH)

In statistical terms, volatility means conditional variance. Therefore, we use Bollerslev's (1986)[13]GARCH model to estimate conditional variance and calculate volatility in historical house prices. When compared to traditional ARCH models, GARCH has greater explanatory power. This study also applies Engle's (1982) [14] Lagarange multiplier (LM) to test whether the variance of residual terms has a heteroskedastic volatility effect.The classic $\operatorname{GARCH}(\mathrm{m}, \mathrm{n})$ model is expressed as below.

$$
\sigma_{t}^{2}=\alpha_{0}+\sum_{i=1}^{n} \alpha_{i} \varepsilon_{t-i}^{2}+\sum_{i=1}^{m} \beta_{i} \sigma_{t-i}^{2}
$$

Where $\alpha_{0}$ is the drift term, $\alpha_{i}$ and $\beta_{i}$ are regression coefficients, $\varepsilon_{t}^{2}$ is the square of the residual term at period $t$, and $\sigma_{t}^{2}$ is conditional variance at period $t$.

STEP4House Price Annual Volatility Switching

Using the ARMA(p,q)-GARCH(m,n) time switching models established above, we can obtain house price volatility in each period. Then according toHull(2002)[15], it is necessary to convert the house price volatility in each period into a mean volatility. This calculation is shown in Equation (18), below.

$$
E_{t}[\bar{\sigma}]=\sqrt{\sigma_{L}^{2}+\frac{1}{T} \frac{1-\left(\alpha_{0}+\beta_{0}\right)^{T}}{1-\left(\alpha_{0}+\beta_{0}\right)}\left[\sigma_{t+1}^{2}-\sigma_{L}^{2}\right]}
$$

Where $\sigma$ is mean volatility, $t$ is the current time point, $T$ is the future date of expiration, $\sigma_{L}^{2}$ is long term mean volatility, and $\alpha_{0}$ and $\beta_{0}$ are regression coefficients.

STEP5Monte Carlo Simulation of Cash Flow for Real Estate Investment Projects

Based on the special characteristics of advanced sales in real estate investment projects, this study divides real estate cash flow into four main periods: land purchase, advanced sales, building construction, and completion of construction. These four periods are used to construct a model for a project cash flow model, which is entered into the Monte Carlo simulation. Since house prices are the key influence on property values, this variable is simulated in the model as a random variable. The calculation is shown in Equation (19), below.

$$
P V=\sum_{t=0}^{t} \frac{C F_{t}}{(1+i)^{t}}
$$

Where PV is revenue present value, $\mathrm{I}$ is the discount rate, $C F_{t}$ is revenue cash flow period, and $T$ is the investment rights period. Finally, after the after the mean and standard deviation of the project revenue present value are simulated, these are converted into project volatility $\sigma$ and anticipated growth rate $\mu_{V}$. Project volatility is expressed as $\sigma=\frac{\sigma_{t}}{V_{0}}$, where $\sigma_{t}$ is the standard deviation in project value, and $V_{0}$ is the initial present value of project revenue. Anticipated growth rate is expressed as $\mu_{v}=\frac{\bar{V}-V_{0}}{V_{0}}$, where $\bar{V}$ is mean revenue present value and $V_{0}$ is the initial present value of project revenue.

\section{References}

[1] L. Trigeorgis, S. P. Manson. Valuing Managerial Flexibility. Midland Corporate Finance Journal, 5, 14-21 (1987).

[2] S. J. Titman. Urban Land Prices under Uncertainty. The American Economic Review, 75, 505-514 (1985).

[3] J. T. Williams. Real estate development as an option. The Journal of Real Estate Finance and Economics, 4, 191-208 (1991).

[4] L. Trigeorgis. Real Option and Interactions with Financial Flexibility. Financial Management, 22, 65-77 (1993).

[5] L. J. Quigg. Empirical Testing of Real Option-Pricing Models. The Journal of Finance, XLVIII, 621-640 (1993).

[6] S. R. Grenadier. The Strategic Exercise of Options: Development Cascades and Overbuilding in Real Estate Markets. The Journal of Finance,LI, 1653-1679 (1996).

[7] K. Rocha, L. Salles, F. A. A. Garcia, J. A. Sardinha, J. P. Teixeira. Real estate and real options-A case study. Emerging Markets Review, 8, 67-79 (2007).

[8] I. E. Farissi, J. M. Sahutb, and M.Bellalahc. Evaluation of Real Options with Information Costs. International Journal of Business, 13, (2008)

[9] R. Buttimer, S. P. Clark, and S. H. Ott. Land Development: Risk, Return and Risk Management. The Journal of real estate finance and economic, 36, 81-102 (2008).

[10] X. Y. Ke, F. Q. Diao, K. J. Zhu. A Real Option Model Suitable for Real Estate Project Investment Decision," Journal of Advanced Materials Research, 225, 234-238 (2011).

[11] E. Said, A. Dickey. Testing for Unit Roots in ARMA Models of Unknown Order. Biometrika, 71, 599-607 (1984).

[12] G. E. P. Box, G. M. Jenkins. Time Series Analysis Forecasting and Control,2nd ed, Holden-Day, San Francisco, (1976).

[13] T. Bollerslev. Generalized Autoregressive Conditional Heteroskedasticity. Journal of Econometrics, 33, 307-327 (1986)

[14] R. F. Engle. Autoregressive Conditional Heteroskedasticity with Estimates of the Variance of U. K. Inflation. Econometrica, 50, 987-1008 (1982).

[15] J. Hull. Options,Futures, and Other Derivatives,5th edition, Prentice Hall International,Inc, (2002). 